\title{
Gene Expression Changes Induced by Genistein in the Prostate Cancer Cell Line LNCaP
}

\author{
Suvarna Bhamre ${ }^{1, \#}$, Debashis Sahoo ${ }^{2, \#}$, Robert Tibshirani ${ }^{3}$, David L. Dill ${ }^{4}$ and James D. Brooks ${ }^{1, *}$ \\ ${ }^{I}$ Department of Urology, Stanford University, Stanford, California, USA \\ ${ }^{2}$ Department of Chemical Engineering, Stanford University, Stanford, California, USA \\ ${ }^{3}$ Department of Health Research and Policy, Stanford University, Stanford, California, USA \\ ${ }^{4}$ Department of Computer Science, Stanford University, Stanford, California, USA
}

\begin{abstract}
Epidemiological evidence suggests that soy consumption is associated with a decreased risk of prostate cancer. The isoflavone genistein is found at high levels in soy and a large body of evidence suggests it is important in mediating the cancer preventive effects of soy. The mechanisms through which genistein acts in prostate cancer cells have not been fully defined. We used gene expression profiling to identify genes significantly modulated by low and high doses of genistein in LNCaP cells. Significant genes were identified using StepMiner analysis and significantly altered pathways with Ingenuity Pathways analysis. Genistein significantly altered expression of transcripts involved in cell growth, carcinogen defenses and steroid signaling pathways. The effects of genistein on these pathways were confirmed by directly assessing dose-related effects on LNCaP cell growth, NQO-1 enzymatic activity and PSA protein expression. Genistein produces diverse effects on gene expression that are dose-dependent and this has important implications in developing genistein as a putative prostate cancer preventive agent.
\end{abstract}

Keywords: Soy, genistein, microarray, gene expression, prostate cancer, cancer prevention.

\section{INTRODUCTION}

Prostate cancer incidence and death rates are vastly different between Asian countries, where they are very low, and the United States and Northern Europe, where they among the highest for all malignancies [1]. Studies of Asian emigrants show dramatic increases in prostate cancer rates within a generation of arriving in the West suggesting environmental factors underlie much of this discrepancy [2]. Many studies have implicated diet as the most important environmental risk factor and have led to the hypothesis that dietary modifications or consumption of critical micronutrients could serve as an important prostate cancer preventive strategy [3]. One of the most striking dietary differences is the level of soy-based foods consumed in Asian countries compared to the West. Soy contains many bioactive compounds, including high levels of isoflavones. Compared to Western men, Asians have dramatically higher plasma levels of soy isoflavones and other soy components. Epidemiological studies have shown significant correlation between plasma soy isoflavone concentrations and subsequent risk being diagnosed with prostate cancer, developing metastatic prostate cancer and dying of prostate cancer [4-7].

\footnotetext{
*Address correspondence to this author at the Department of Urology, Room S287, Stanford University School of Medicine, 300 Pasteur Drive, Stanford, CA 94305-5118, USA; Tel: (650) 725-5544; Fax: (650) 723-0765; E-mail: jdbrooks@stanford.edu

${ }^{\#}$ Contributed equally to this manuscript
}

The isoflavone genistein has emerged as one of the most interesting and intensively studied micronutrients. Genistein has been shown to exert a number of effects in cancer cells including alteration of steroid hormone signaling, inhibition of angiogenesis, inhibition of cancer cell invasion, and suppression of cell growth and proliferation [8-15]. Genistein has also been shown to slow the growth of prostate cancer xenografts and decrease tumor growth in carcinogen-induced and transgenic prostate cancer models $[7,16,17]$. However, the effects of genistein can differ depending on dose used and cancer type, and high levels of genistein have been found to promote growth of estrogen receptor positive breast cancers [7]. Therefore, understanding the mechanisms of action of genistein at different concentrations could be important in developing future preventive strategies.

We have used gene expression profiling to understand signaling pathways activated after treatment of prostate cells with candidate preventive agents [18-23]. One challenge in interpreting these studies is identifying transcripts that show a statistically robust change over a time course after treatment. Selection of genes using an arbitrary cut-off, such as 2 -fold change over the time course, introduces many falsepositive transcripts and misses others that might be important but are only slightly below the arbitrary cut-off. Recently, we have used a statistical tool, StepMiner, to identify genes that show a significant change after treatment of prostate cancer cells with sulforaphane [21]. Pathway analysis of genes that changed significantly over time revealed that sul- 
foraphane potently induced a number of genes involved in carcinogen defenses, and blocked cell growth at G2/M. To gain insights into the possible mechanisms of action of genistein in LNCaP prostate cancer cells, we have performed gene expression profiling, StepMiner and pathways analysis.

\section{MATERIALS AND METHODS}

\section{Cell Culture and Treatment}

LNCaP cells were grown in RPMI 1640 medium supplemented with $10 \%$ fetal bovine serum, penicillin (100 units $/ \mathrm{ml})$ and streptomycin $(100 \mu \mathrm{g} / \mathrm{ml})$ in a humidified atmosphere at $37^{\circ} \mathrm{C}$ and $5 \% \mathrm{CO}_{2}$. When cells reached $75 \%$ confluence, they were treated with either $2 \mu \mathrm{M}$ or $15 \mu \mathrm{M}$ genistein (Sigma-Aldrich, St. Louis, MO) dissolved in DMSO, or DMSO only (controls). Cells were harvested at selected times after treatment and prior to reaching confluency by scraping in TRIzol solution (InVitrogen, Carlsbad, CA) and total RNA was isolated according to manufacturer's instructions.

\section{Microarray Hybridizations and Data Analysis}

Gene expression analysis was performed using spotted cDNA microarrays manufactured at Stanford University containing 42,000 elements representing 24,164 genes. Total RNAs $(80 \mu \mathrm{g})$ isolated from genistein treated and control cells were reverse transcribed and the cDNAs were fluorescently labeled by incorporation of $\mathrm{Cy}-5$ (genistein treated) or Cy-3 (control) labeled dUTP during the reaction. Labeled cDNAs from treated and control cells matched by time point were mixed and hybridized to the microarrays according to previously described methods [24].

After 14 hours the fluorescence intensities for each spot (and background) for both channels of each microarray were determined using a GenePix scanner and software as we have reported previously. Data files containing fluorescence ratios for each spot were entered into the Stanford Microarray Database [25]. The raw data from all experiments is available for downloading and has been deposited in GEO (GSE24796).

\section{StepMiner Analysis}

The StepMiner algorithm analyzes microarray time courses by identifying genes that undergo abrupt transitions in expression level (steps) over the time course [26]. The algorithm iteratively compares mean expression levels immediately prior to a time point to the mean expression levels of all subsequent time points and tests for a significant difference between these sets of expression values. To improve detection of early changes in gene expression, we use seven replications for the zero hour (no treatment). Time points assessed for $2 \mathrm{uM}$ genistein and $15 \mathrm{uM}$ genistein included 4 , $8,12,18,24,36$ and 48 hours. These time course datasets were analyzed using StepMiner [26]. Genes that are significantly (p-value < 0.05) up-regulated and down-regulated were retrieved using StepMiner. The common significantly regulated genes in both time courses were found by intersecting the significant genes in both genistein concentrations. StepMiner results with a complete listing of significant genes are available at $\mathrm{http}: / /$ genepyramid.stanford.edu/microarray/ Genestein/

\section{Advanced Gene Set Analysis}

The Unigene clusters ID for the significant genes were retrieved separately for the $2 \mu \mathrm{M}$ and $15 \mu \mathrm{M}$ genistein time course experiments and significant biological functions, networks and pathways were determined using Ingenuity Pathways Analysis (Ingenuity ${ }^{\circledR}$ Systems, www.ingenuity. com) [27]. Significant biological functions, networks and pathways were reported along with p-values.

\section{Comparison With Cell Cycle Genes}

The significant genes in each experiment were analyzed for enrichment of cell cycle related genes as we have reported previously $[18,20,21]$. The list of cell cycle genes with their annotations was downloaded from http://genomewww.stanford.edu/Human-CellCycle/Hela/data.shtml [28]. A hypergeometric test was performed to test the enrichment of genes related to different cell cycle phases in each time course experiment.

\section{Cell Growth Assays}

24 well culture dishes were plated with $\mathrm{LNCaP}$ cells $\left(5 \times 10^{4}\right.$ cells per well) and the cells were allowed to attach for 18 hours. Cells were treated with genistein at concentrations of $1 \mu \mathrm{M}, 10 \mu \mathrm{M}, 20 \mu \mathrm{M}$ and $50 \mu \mathrm{M}$ for 3 days, during which time the cells did not reach confluence. DMSO concentration in control wells did not exceed $0.1 \%$. Cells were harvested by trypsinization and counted on a hemacytometer using a light microscope. Cell viability was determined by the trypan blue $(0.1 \% \mathrm{w} / \mathrm{v})$ exclusion assay.

\section{PSA Quantitation}

Six-centimeter culture dishes were seeded with $7 \times 10^{5}$ cells/plate and allowed to adhere for 18 hours in RPMI media containing $10 \%$ FBS. The cell media in one set of wells was changed to $10 \%$ FBS RPMI and in the other set to $10 \%$ charcoal stripped serum RPMI. Cells were treated with either $0.1 \%$ DMSO; $10 \mu \mathrm{M}$ DHT; $15 \mu \mathrm{M}$ Genistein or $15 \mu \mathrm{M}$ Genistein plus $10 \mu \mathrm{M}$ DHT. Media was assayed for secreted total PSA using a human prostate specific antigen ELISA kit (DSL-10-9700; Diagnostic Systems Laboratories, Inc., Houston. TX). Values were normalized to total protein of cells (without media) cultured in the same well from which the medium was taken. All experiments were performed in triplicate.

\section{NADPH Dehydrogenase, Quinone 1 (NQO1) Enzymatic Activity Assay}

After aspirating the media, treated and control cells cultured in a 96-well plate were lysed with $200 \mu$ of $0.08 \%$ digitonin (Sigma-Aldrich) $/ 2 \mathrm{mM}$ EDTA (pH 8.0) at $37^{\circ} \mathrm{C}$ for $30 \mathrm{~min}$. NQO1 enzymatic activity was assessed in triplicate by the menadione-coupled reduction of tetrazolium dye as described previously [29, 30]. Enzymatic activity for each sample was normalized to total cell protein in each sample.

\section{RESULTS}

Genistein induced significant changes in gene expression in $\mathrm{LNCaP}$ at $2 \mu \mathrm{M}$ and $15 \mu \mathrm{M}$ final concentration in the media. For genistein $2 \mu \mathrm{M}$, StepMiner analysis identified 2033 genes that showed a significant increase or decrease over the 
48 hour time course, while 1449 transcripts were significantly altered for genistein $15 \mu \mathrm{M}$ (Fig. 1). Somewhat surprisingly, only 323 transcripts were common to the 2 concentrations, suggesting significant dose effects on gene expression. Most time-dependent changes in gene expression occurred by 24 hours for both doses, with very few transcripts increasing or decreasing after that time.

To gain insights into the function effects of genistein on cellular functions and pathways, we used Ingenuity Pathways Analysis to analyze gene expression data for enrichment of classes of transcripts [27]. Given the significant differences in the genes modulated by the different doses of genistein, we analyzed each dose separately. Not surprisingly, in cells treated with $2 \mu \mathrm{M}$ genistein the differentially expressed transcripts were enriched most significantly in gene and protein expression cellular functions (Table 1). In addition, transcripts associated with the cell cycle were significantly modulated. Intriguingly, genistein $2 \mu \mathrm{M}$ produced effects in steroid (estrogen and glucocorticoid) signaling, and inositol metabolism. At the higher dose, genistein displayed somewhat different effects on cellular functions with alteration of transcripts associated with cell growth, cell death and
DNA damage (Table 2). Genistein $15 \mu \mathrm{M}$ also induced cell stress and activated xenobiotic defense pathways including aryl hydrocarbon receptor signaling and Nrf2- stress response pathways. Based on these analyses we investigated the effects of genistein on cell growth, cellular defense pathways and steroid hormone signaling.

\section{Effects of Genistein on Prostate Cancer Cell Growth}

For both doses, genistein modulated transcripts associated with cell proliferation and the cell cycle. Previous work has shown that genistein can inhibit prostate cancer cell growth in vitro and in vivo $[7,14,16]$. To confirm that genistein inhibited cell growth in LNCaP cells used in gene expression analysis, we cultured cells in the presence of genistein and determined cell count after 3 days (Fig. 2). Genistein showed a clear dose effect on cell growth, with demonstrable inhibition starting at doses of $1 \mu \mathrm{M}$ and visible cell death at concentrations greater than $50 \mu \mathrm{M}$. To gain a better understanding of the pathways involved in inhibition of LNCaP growth, we compared the genes identified by StepMiner to a set of genes that vary periodically as synchronized cells move through the cell cycle [28] (Fig. 3). Typi-

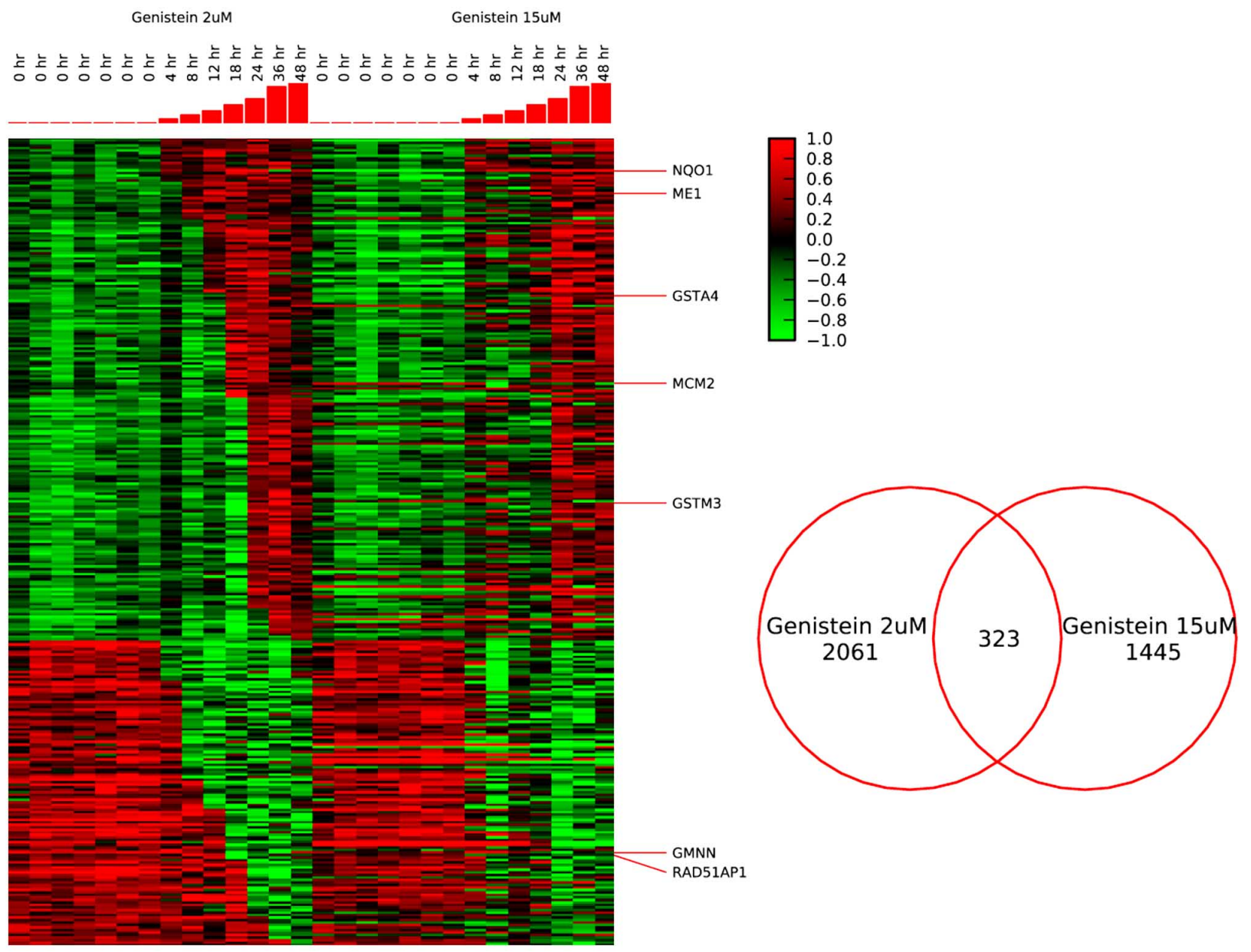

Fig. (1). Heatmap of gene expression of the 323 genes modulated significantly over the time course by genistein $2 \mu \mathrm{M}$ and $15 \mu \mathrm{M}$ as identified by StepMiner analysis. Each time point is represented in a column and individual transcripts are displayed in rows. Red indicates relative induction of transcripts while green represents relative decrease in expression levels, while the degree of color saturation corresponds to the degree of change (key to the right of the heat map). To the right, a Venn diagram illustrates the total number of transcripts identified as significantly changed over time by StepMiner analysis for genistein $2 \mu \mathrm{M}$ and $15 \mu \mathrm{M}$ with the corresponding overlap between the datasets. A complete list of significant genes for each concentration is available at http://genepyramid.stanford.edu/microarray/Genestein/ 
Table 1. Cellular Functions and Pathways Significantly Modulated by Genistein $2 \mu \mathrm{M}$

\begin{tabular}{|l|l|l|}
\hline Cellular Function & $\boldsymbol{p}$-value & Adjusted $\boldsymbol{p}$-value* \\
\hline \hline Gene expression & $<0.0005$ & 0.05 \\
\hline Cell cycle & $<0.0005$ & 0.05 \\
\hline Protein synthesis & 0.0005 & 0.006 \\
\hline Post-translational modification & 0.002 & 0.03 \\
\hline RNA post transcriptional modification & 0.002 & 0.02 \\
\hline Canonical pathways & & \\
\hline Estrogen receptor signaling & 0.001 & \\
\hline Inositol metabolism & 0.008 & \\
\hline Inositol phosphate metabolism & 0.01 & \\
\hline Glucocorticoid receptor signaling & 0.02 & \\
\hline Nicotinate and nicotinomide metabolism & 0.02 & \\
\hline
\end{tabular}

*P-values corrected for multiple hypothesis testing.

Table 2. Cellular Functions and Pathways Significantly Modulated by Genistein $15 \mu \mathrm{M}$

\begin{tabular}{|l|l|l|}
\hline Cellular Function & p-value & Adjusted p-value* \\
\hline \hline Cell cycle & $<0.0005$ & 0.05 \\
\hline DNA replication, recombination, repair & $<0.0005$ & 0.05 \\
\hline Cell death & $<0.0005$ & 0.05 \\
\hline Cellular development & $<0.0005$ & 0.05 \\
\hline Cell growth and proliferation & $<0.0005$ & 0.05 \\
\hline Canonical pathways & & \\
\hline BRCA1 in DNA damage response & 0.0001 & \\
\hline Aryl hydrocarbon receptor signaling & 0.0003 & \\
\hline p53 signaling & 0.0005 & \\
\hline Nrf2-mediated stress response & 0.003 & \\
\hline CCR3 signaling & 0.004 & \\
\hline
\end{tabular}

*P-values corrected for multiple hypothesis testing.

cally, there is enrichment of highly expressed transcripts in the particular phase of the cell cycle in which growth arrest occurs. We performed a hypergeometric test to evaluate whether enrichment for transcripts was observed for either of the concentrations of genistein (Table in Fig. 3). In the case of genistein, we observed no enrichment of transcripts for any phase of the cell cycle, implying that genistein causes global suppression of LNCaP cell growth.

\section{Genistein Induces Carcinogen Defenses}

Normally, exogenous and endogenous reactive species are detoxified by a series of enzymatically catalyzed oxidation (Phase 1) and reduction (Phase 2) reactions [31]. Induc- tion of phase 2 enzymes has been long associated with protection against carcinogenesis [32]. Many phase 2 enzymes are regulated transciptionally by the Nrf2 signaling pathway [33], and this pathway was identified as modulated significantly by the IPA analysis. Genistein significantly upregulated many known phase 2 enzyme transcript levels including glutathione transferases (GSTA4, GSTM1), malic enzyme (ME1), and NADPH Dehydrogenase, Quinone 1 (NQO1) (see Fig. 1). Within 4 hours of treatment, genistein $15 \mu \mathrm{M}$ induced transcript levels of the gammaglutamylcysteine synthetase regulatory subunit GCLM, which catalyzes the rate-limiting step of glutathione synthesis (confirmed by qPCR at $4,18,36$ and 48 hours after treatment, not shown). To evaluate the effects of genistein on 


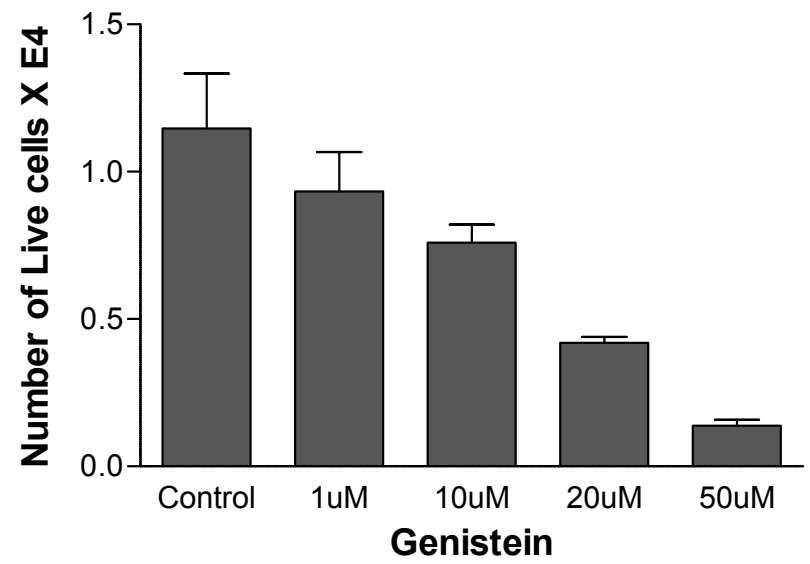

Fig. (2). Relative number of live cells after treatment for 72 hours with genistein. Depicted are mean numbers of live cells \pm standard error of 3 replicates.

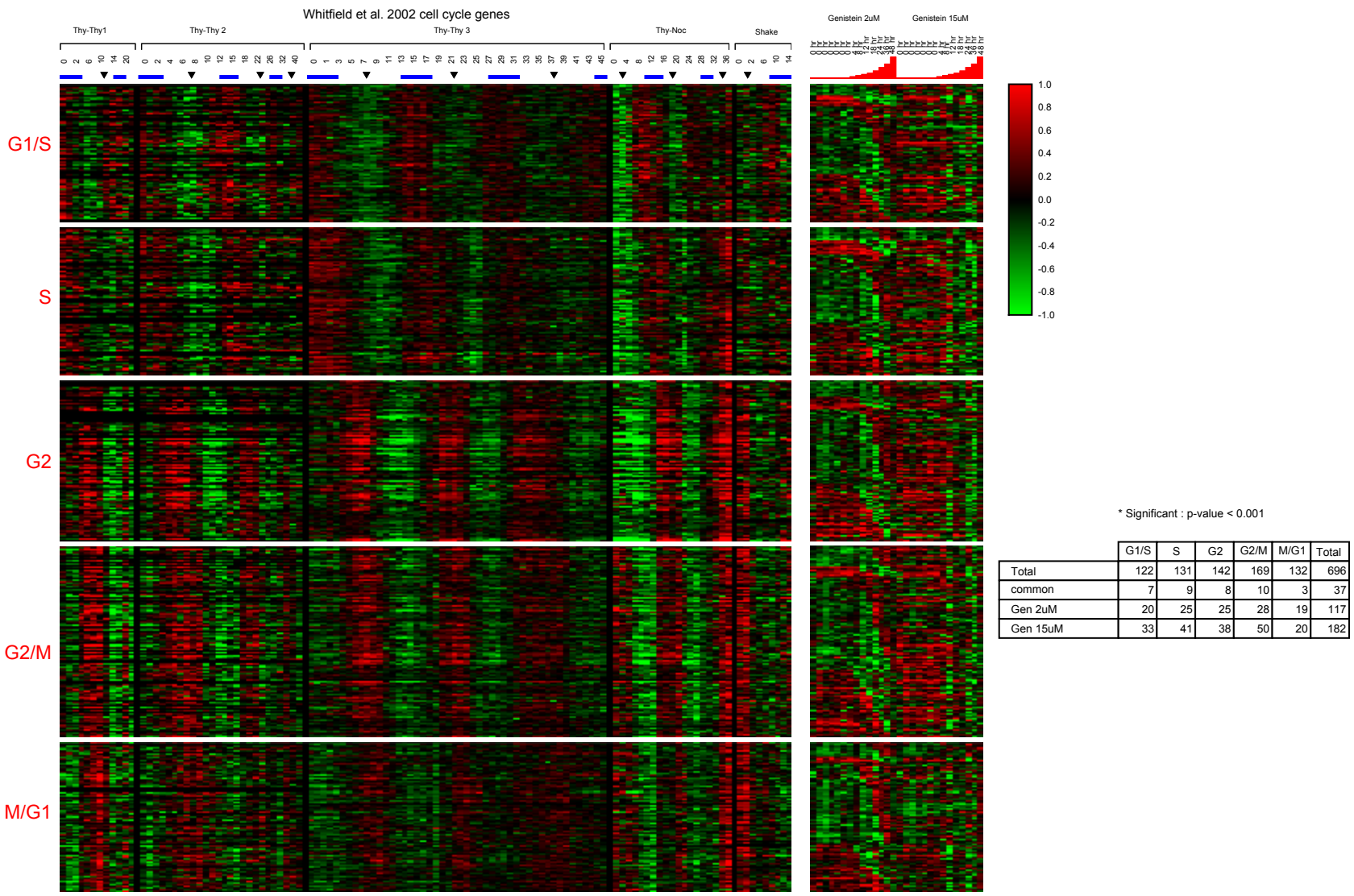

Fig. (3). Comparison of genes modulated as cells pass through the cell cycle from Whitfield et al. [28] to the transcript profiles significantly altered by genistein $2 \mu \mathrm{M}$ and $15 \mu \mathrm{M}$. Data are shown for each of the five cell cycle time courses (114 total arrays), and two genistein time courses (21 total arrays). The blue bars above each column represent $\mathrm{S}$ phase and the arrows indicate mitoses as estimated by flow cytometry or BrdU labeling. The cell cycle data were acquired by arresting cell growth by double thymidine (Thy-Thy) or nocodazole (Thy-Noc) block, followed by release of blockade (shake) so that the cells pass synchronously through the cell cycle. In cell cycle each time course, RNA was collected for points (typically every 1-2 h) for $30 \mathrm{~h}$ (Thy-Thy1), $44 \mathrm{~h}$ (Thy-Thy2), $46 \mathrm{~h}$ (Thy-Thy3), $36 \mathrm{~h}$ (Thy-Noc), or $14 \mathrm{~h}$ (Shake) after the synchronous arrest, at the intervals indicated. The genistein time courses are shown at the right for comparson. Over the time course, the majority of transcripts in the genistein experiments show decreased expression, consistent with decreased cell growth. Transcripts modulated significantly by genistein are broken down by phase in the cell cycle where they normally show increased expression in the table at the right. Compared to the complete cell cycle dataset, genistein at either concentration did not show enrichment for any phase in the cell cycle by a hypergeometric test. 
phase 2 enzyme activity, we assessed NQO1 activity using the menadione-coupled reduction of tetrazolium dye that has been used widely as a biochemical assay of global phase 2 enzyme activation [34]. Even at relatively low doses, genistein induced a dose-dependent increase in NQO-1 activity in LNCaP cells (Fig. 4).

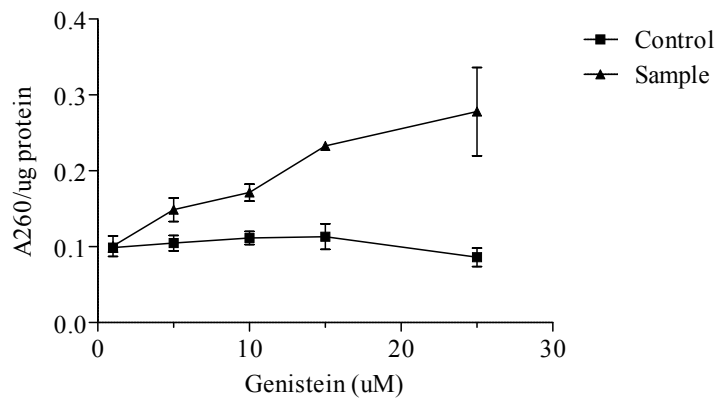

Fig. (4). Fold-induction of NQO1 enzymatic activity over a range of concentrations for $\mathrm{LNCaP}$ after treatment with genistein as measured by the menadione-coupled reduction of tetrazolium. Absorbance at $260 \mathrm{~nm}$ wavelength is normalized to total protein and bars represent standard deviations. Points represent A260 \pm standard error of 3 replicates $(P<0.001$ for genistein treated vs. control by Wilcoxon rank sum test with continuity correction).

\section{Genistein Modulates Androgen Signaling}

Pathway analysis identified estrogen and glucocorticoid signaling as pathways significantly modulated in LNCaP cells by treatment with genistein $2 \mu \mathrm{M}$. To determine whether androgen signaling pathways were influenced by genistein treatment, we compared the transcripts identified by StepMiner to a set of transcripts we have identified previously as significantly modulated by treatment of LNCaP cells with androgens [35] (Fig. 5). Genistein $2 \mu \mathrm{M}$ appeared to induce somewhat mixed effects on androgen signaling with increased expression of several genes known to be repressed by androgen, and decreased expression of genes known to be induced by androgen (Table 3). On the other hand, genistein $15 \mu \mathrm{M}$ appeared to induce expression changes opposite those of androgen. For instance, genes suppressed by both androgen and genistein were quite few $(\mathrm{n}=4, P=0.8$, standard hypergeometric test), while the number of genes decreased by androgen but increased by genistein was highly significant (n=28, $P<1 \times 10^{7}$, standard hypergeometric test). Genes normally induced by androgen were uncommonly induced by genistein $(n=44, P=0.06$, standard hypergeometric test) but a significantly number of androgen-induced genes were suppressed by genistein $\left(\mathrm{n}=68, P<1 \times 10^{8}\right.$, standard hypergeometric test). Several genes associated with proliferative effects of androgen (e.g. TMPRSS2, NKX3A) were suppressed by genistein and suppression of NKX3A suppression was confirmed by qPCR (not shown). To further assess the effects of genistein on androgen signaling, we assayed prostate specific antigen levels in the media of cultured LNCaP cells (Fig. 6). Genistein $15 \mu \mathrm{M}$ suppressed PSA protein levels in the media both in androgen depleted (Charcoal stripped) and normal media, as well as in the presence of high levels of androgen produced by simultaneous treatment with dihydrotestosterone (DHT) $10 \mu \mathrm{M}$.

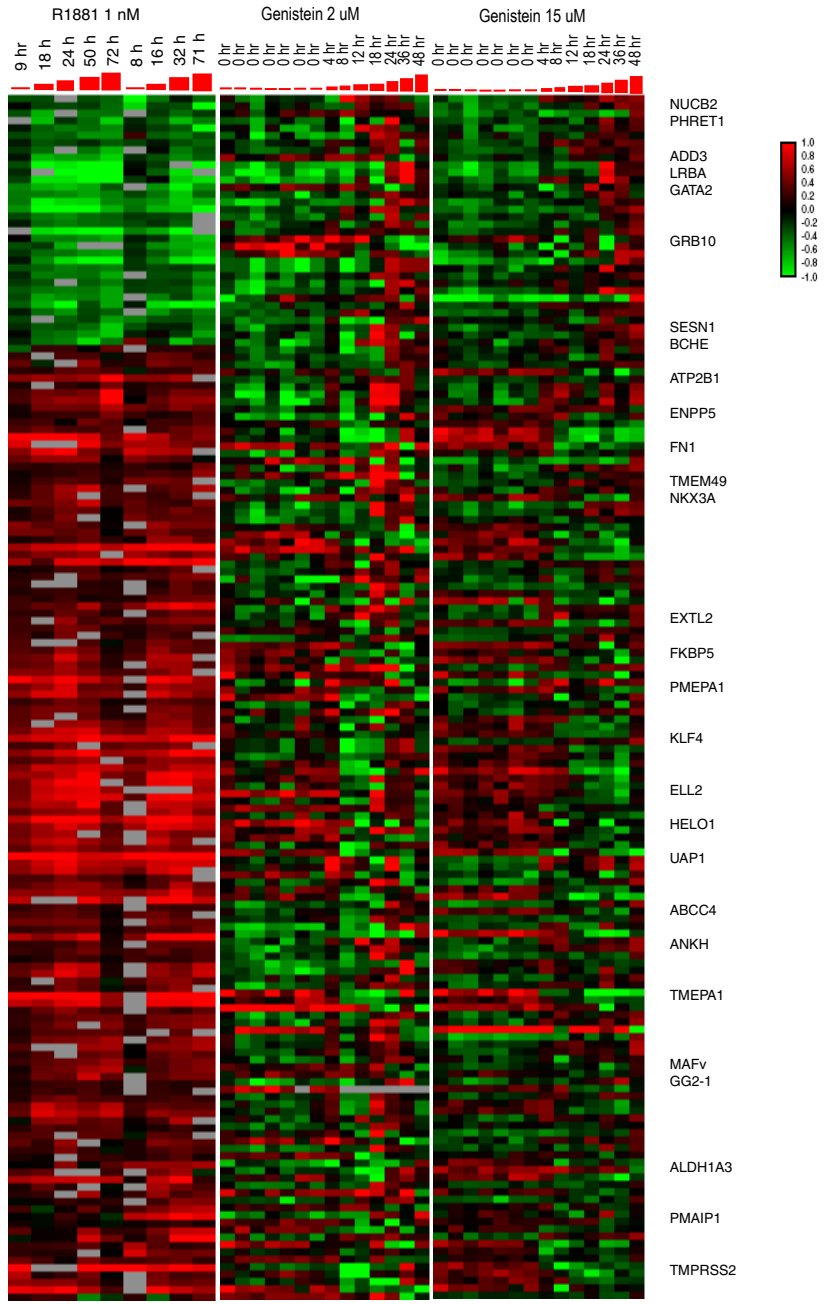

Fig. (5). Androgen-responsive genes modulated by Genistein. The left heatmap shows 2 separate time courses of androgen-responsive transcripts identified by DePrimo et al. [35] by treating LNCaP cells with R1881 at $1 \mathrm{nM}$. On the right are the corresponding transcript levels after treatment with genistein $2 \mu \mathrm{M}$ and $15 \mu \mathrm{M}$ for which there was a significant change in expression over the time course at one of the concentration levels. The heterogeneous appearance of the heatmaps corresponds to the mixed effects of genistein on androgen responsive genes and is most pronounced at genistein $2 \mu \mathrm{M}$. At genistein $15 \mu \mathrm{M}$, many transcripts upregulated by androgen are suppressed significantly based on a standard hypergeometric test (see text).

\section{DISCUSSION}

Genistein significantly alters expression levels of many transcripts in the prostate cancer cell line LNCaP. Furthermore, the profile of transcripts altered in response to genistein differs significantly between a relatively low dose $(2 \mu \mathrm{M})$ and a much higher dose $(15 \mu \mathrm{M})$, although we did find many transcripts in common between the 2 doses. The many gene expression differences between these doses are not surprising given the differing effects we observed on cell growth, phase 2 enzyme induction and androgen signaling of different doses of genistein on LNCaP cells. These findings argue for caution in extrapolating gene expression findings to prostate tissues in vivo. Investigation of the potential 
Table 3. Androgen Regulated Genes Modulated Significantly by Genistein

\begin{tabular}{|c|c|c|c|}
\hline Clone ID & $\begin{array}{l}\text { Genes Down-Regulated by } \\
\text { Androgen (Ref.35) }\end{array}$ & $\begin{array}{l}\text { 2uM Genistein up-Regulated Genes } \\
\text { (Fold Change) }\end{array}$ & $\begin{array}{l}\text { 15uM Genistein up-Regulated Genes } \\
\text { (Fold Change) }\end{array}$ \\
\hline IMAGE:78294 & UGT2B15 & - & 5.31 \\
\hline IMAGE:1461664 & BCHE & - & 2.62 \\
\hline IMAGE:773138 & CAMK2N1 & 2.35 & 2.52 \\
\hline IMAGE:299737 & ATP2B1 & 1.56 & 2.11 \\
\hline IMAGE:565379 & GRB10 & - & 2.07 \\
\hline IMAGE:813584 & SESN1 & - & 2.04 \\
\hline IMAGE:379709 & LRRN1 & - & 2.03 \\
\hline IMAGE:815794 & NUCB2 & - & 1.9 \\
\hline IMAGE:503602 & CAMK2N1 & 2.27 & 1.89 \\
\hline IMAGE:284701 & FOLH1 & - & 1.73 \\
\hline IMAGE:376516 & LRBA & - & 1.66 \\
\hline IMAGE:838689 & SLC44A1 & 2.03 & 1.65 \\
\hline IMAGE:767346 & C14orf4 & - & 1.65 \\
\hline IMAGE:796323 & ADD3 & - & 1.59 \\
\hline IMAGE:609155 & LRRN1 & 1.33 & 1.46 \\
\hline IMAGE:322461 & ENPP5 & - & 1.46 \\
\hline IMAGE:245531 & HIBADH & - & 1.45 \\
\hline IMAGE:298128 & DDEF2 & - & 1.44 \\
\hline IMAGE:236412 & C14orf4 & - & 1.33 \\
\hline IMAGE:786288 & SLC20A2 & - & 1.3 \\
\hline IMAGE:502369 & PDCD5 & 2.14 & - \\
\hline IMAGE: 135688 & GATA2 & 1.78 & - \\
\hline IMAGE:813854 & PURA & 1.76 & - \\
\hline IMAGE:1535156 & NUDT4 & 1.69 & - \\
\hline IMAGE:149809 & GATA2 & 1.69 & - \\
\hline IMAGE:740914 & CTBP1 & 1.5 & - \\
\hline IMAGE:2548606 & СТВP1 & 1.42 & - \\
\hline
\end{tabular}


Table 3. contd....

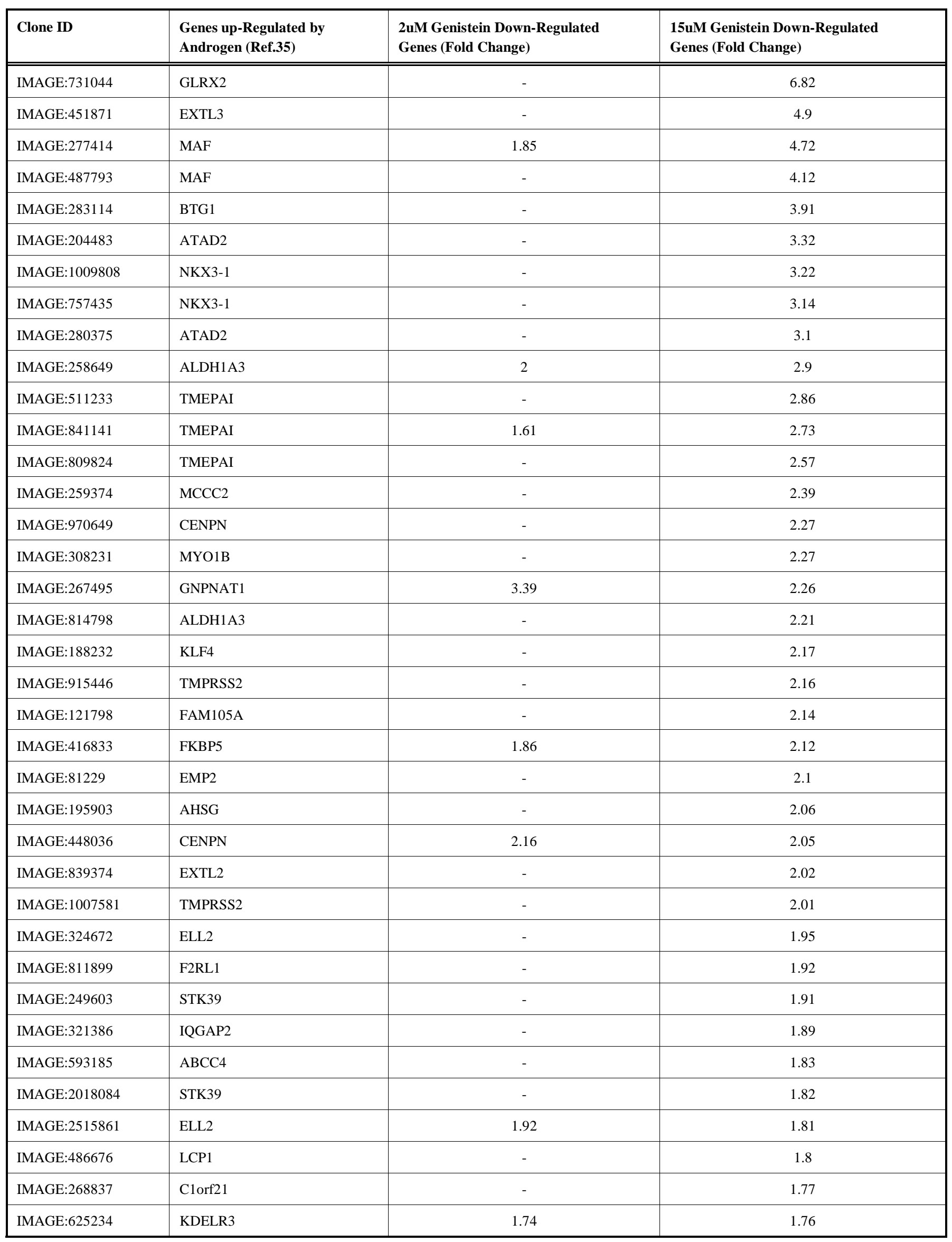


Table 3. contd....

\begin{tabular}{|c|c|c|c|}
\hline Clone ID & $\begin{array}{l}\text { Genes up-Regulated by } \\
\text { Androgen (Ref.35) }\end{array}$ & $\begin{array}{l}\text { 2uM Genistein Down-Regulated } \\
\text { Genes (Fold Change) }\end{array}$ & $\begin{array}{l}\text { 15uM Genistein Down-Regulated } \\
\text { Genes (Fold Change) }\end{array}$ \\
\hline IMAGE:83156 & HEBP2 & 2.11 & 1.75 \\
\hline IMAGE: 1048810 & BRP44 & - & 1.74 \\
\hline IMAGE:61626 & LOC56902 & - & 1.73 \\
\hline IMAGE:377048 & MYO1B & - & 1.71 \\
\hline IMAGE:627401 & TNFAIP8 & - & 1.7 \\
\hline IMAGE:565235 & SMS & - & 1.68 \\
\hline IMAGE:134719 & ZBTB10 & - & 1.68 \\
\hline IMAGE:293569 & C1orf21 & - & 1.66 \\
\hline IMAGE:594482 & TBRG1 & - & 1.64 \\
\hline IMAGE:342211 & MBOAT2 & 1.23 & 1.64 \\
\hline IMAGE:344589 & LCP1 & - & 1.59 \\
\hline IMAGE:292515 & UAP1 & - & 1.59 \\
\hline IMAGE:2551468 & GUCY1A3 & - & 1.59 \\
\hline IMAGE:320797 & EXTL2 & - & 1.58 \\
\hline IMAGE:310493 & ACSL3 & - & 1.58 \\
\hline IMAGE:306066 & ELOVL7 & - & 1.57 \\
\hline IMAGE:412949 & TBRG1 & - & 1.56 \\
\hline IMAGE:1855393 & ZBTB10 & - & 1.54 \\
\hline IMAGE:755238 & ABCA5 & - & 1.52 \\
\hline IMAGE:1569107 & PAK1IP1 & - & 1.51 \\
\hline IMAGE:138265 & IL1R1 & - & 1.5 \\
\hline IMAGE:809858 & COPS7A & - & 1.48 \\
\hline IMAGE:767469 & ANKH & - & 1.47 \\
\hline IMAGE:795498 & ABHD2 & - & 1.43 \\
\hline IMAGE:773478 & TNK2 & - & 1.43 \\
\hline IMAGE:625875 & ERO1L & - & 1.4 \\
\hline IMAGE: 1520937 & ANKH & - & 1.4 \\
\hline IMAGE:292236 & ABHD2 & - & 1.39 \\
\hline IMAGE:111812 & C15orf 23 & - & 1.39 \\
\hline IMAGE:428431 & PKIB & - & 1.37 \\
\hline IMAGE:510060 & PCF11 & - & 1.29 \\
\hline IMAGE:998080 & TMED2 & 18.34 & - \\
\hline IMAGE:447404 & INTS10 & 7.83 & - \\
\hline IMAGE:435611 & SLC33A1 & 2.84 & - \\
\hline IMAGE:755765 & PGM3 & 2.61 & - \\
\hline IMAGE:263227 & C19orf42 & 2.54 & - \\
\hline IMAGE:2323631 & PGM3 & 2.52 & - \\
\hline
\end{tabular}


Table 3. contd....

\begin{tabular}{|c|c|c|c|}
\hline Clone ID & $\begin{array}{l}\text { Genes Down-Regulated by } \\
\text { Androgen (Ref.35) }\end{array}$ & $\begin{array}{l}\text { 2uM Genistein up-Regulated Genes } \\
\text { (Fold Change) }\end{array}$ & $\begin{array}{l}\text { 15uM Genistein up-Regulated Genes } \\
\text { (Fold Change) }\end{array}$ \\
\hline IMAGE:592594 & LRIG1 & 2.35 & - \\
\hline IMAGE:731261 & WDR41 & 2.22 & - \\
\hline IMAGE:489106 & AGPAT5 & 2.05 & - \\
\hline IMAGE:359835 & SAT & 1.98 & - \\
\hline IMAGE:1468220 & ELL2 & 1.95 & - \\
\hline IMAGE:126829 & DNAJC3 & 1.8 & - \\
\hline IMAGE:814353 & PMAIP1 & 1.59 & - \\
\hline IMAGE:152289 & PKIB & 1.55 & - \\
\hline IMAGE:810328 & PDIA3 & 1.53 & - \\
\hline IMAGE:198694 & LRRC28 & 1.52 & - \\
\hline IMAGE:504536 & UBE2J1 & 1.5 & - \\
\hline IMAGE:884789 & LRRFIP2 & 1.48 & - \\
\hline IMAGE:70203 & GUCY1A3 & 1.41 & - \\
\hline
\end{tabular}

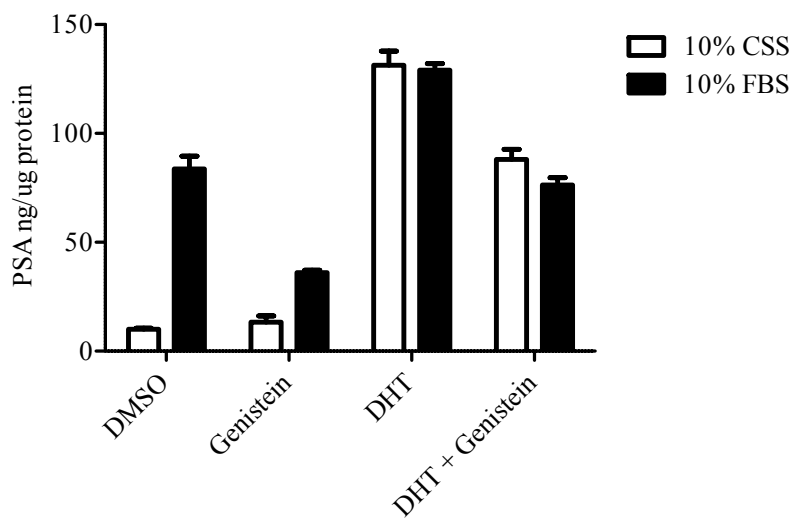

Fig. (6). Genistein decreases the amount of total secreted PSA by cultured LNCaP cells. LNCaP cells grown in either 10\% FBS serum or $10 \%$ charcoal stripped serum with RPMI media were supplemented with DMSO $(0.1 \%)$; DHT (10 $\mu \mathrm{M})$; genistein $(15 \mu \mathrm{M})$; or a combination of DHT $(10 \mu \mathrm{M})$ and genistein $(15 \mu \mathrm{M})$. PSA levels in medium with charcoal stripped serum (CSS, no androgen) are significantly below those of normal fetal bovine serum (FBS, containing androgen) (DMSO columns, $P<0.001)$. Genistein decreases total secreted PSA in the presence of FBS (compare DMSO to genistein, $P<0.01$ ). Genistein decreases PSA in the presence of DHT $1 \mathrm{nM}$ in both CSS and FBS $(P=0.02$ and $P<0.001$, respectively). Depicted are mean media PSA levels \pm standard error of 3 replicates. 
effects of genistein in human prostate tissues should be carried out in the context of precise measurements of genistein and its active metabolites in tissues. While serum levels of genistein in Asian men and men supplemented with soy compounds have been found to be $0.5-0.7 \mu \mathrm{M}$, prostate tissues appear to concentrate genistein to achieve levels that equal or slightly exceed the $2 \mu \mathrm{M}$ concentration we used in the current study $[36,37]$.

At physiologically relevant doses we found significant modulation of transcripts associated with the cell cycle. Our findings on androgen and inositol phosphate pathway modulation and induction of oxidative defenses are consistent with several others who have studied genistein in prostate cancer cells $[10,13,38-43]$. We provide a more comprehensive view of cell cycle regulated genes by capturing all significantly altered transcripts using StepMiner and in direct comparison to a set of genes discovered empirically to vary throughout the cell cycle. Most of the transcripts we observed showed decreased expression, and we did not observe enrichment of transcripts in any particular phase of the cell cycle. Previously we have observed that enrichment of transcripts associated with a particular phase in the cell cycle was associated with arrest in that phase [18, 20, 21]. Based on gene expression profiling, genistein does not appear to provoke cell cycle arrest, but does inhibit cell growth in a dose dependent fashion.

Genistein also alters a number of transcripts associated with response to genotoxic stress. At $15 \mu \mathrm{M}$, genistein significantly increases expression of many transcripts involved in response to and repair of DNA damage, including members of the BRCA1 and p53 signaling pathways. Intriguingly, genistein has been shown previously to not be directly genotoxic by the Ames test [7]. In addition, it does not induce cancers in several species of animals maintained for extended periods on high doses of genistein in their diet [7]. Therefore, it is possible that genistein is able to invoke the stress response through signaling pathways without being mutagenic. Furthermore, genistein induced expression of many genes responsible for carcinogen metabolism, including those regulated by the aryl hydrocarbon receptor (phase 1 and phase 2 genes) as well as those induced exclusively by Nrf-2 signaling (phase 2). Even at low doses of genistein we were able to show induction of NQO1 enzymatic activity, a surrogate of phase 2 enzyme activation [34]. Global induction of carcinogen defense enzymes has been correlated with protection against carcinogen-induced tumors in a variety of model systems [32]. In agreement with our findings, Raschke et al. have shown that genistein induces as set of phase 2 enzymes in the prostate cancer cell line LAPC-4 and attenuates hydrogen peroxide-induced DNA damage [10]. Phase 2 enzyme induction might be particularly relevant to prostate cancer prevention. Loss of expression of the important phase 2 enzyme GSTP1 (pi-class glutathione transferase) occurs early in prostate carcinogenesis and is associated with hypermethylation of deoxycytidine residues in a $\mathrm{CpG}$ island in the GSTP1 gene promoter [44-46]. Therefore, genistein could prevent prostate cancer through compensation for GSTP1 loss by global induction of carcinogen defenses [3].

Genistein also modulated expression of transcripts associated with steroid hormone signaling. We observed that estrogen signaling was significantly modulated in response to $2 \mu \mathrm{M}$ genistein, as was glucocorticoid signaling. Genistein has been shown to have estrogenic effects in breast cancer model systems and estrogens have been used in the treatment of prostate cancer [7]. Genistein has also been shown to have mixed effects on androgen signaling and we observed both androgen promoting and inhibiting effects of genistein with regards to transcript levels. Other laboratories have noted similar modulation of androgen signaling pathways in prostate cancer cells [12]. Although PSA transcript levels were not altered significantly in our dataset, PSA protein was decreased in the media of LNCaP cells. While it is possible that PSA transcript levels account for this decreased expression, genistein has been reported to also act post-transcriptionally to decrease PSA levels [13]. Regardless, since androgen signaling is central to prostate carcinogenesis [47], any modulation of this pathway could play a role in prostate cancer prevention or progression.

While we have focused on the effects of genistein on cell growth, carcinogen defenses and steroid hormone signaling, our data and findings from many other studies suggest that genistein might act through multiple pathways. For example, loss of PTEN gene expression occurs commonly in prostate cancer leading to up-regulation of phosphoinositide-3-kinase (PI3K) signaling pathways [48]. At $2 \mu \mathrm{M}$ genistein, inositol and inositol phosphase pathways were significantly modulated by genistein. Of note, genistein has been shown previously to suppress mTOR signaling [49], and mTOR is an important downstream target of the PI3K signaling pathway that is being evaluated as a therapeutic target.

Given the number of pathways modulated by genistein, understanding its effects in prostate cancer prevention will prove challenging. It is likely that the large numbers of genes modulated are downstream from important regulatory pathways that are affected by genistein, as suggested by our pathway analysis. Whether these are the most important pathways or mechanisms of action of genistein is unknown. In addition, transcriptome profiling can potentially miss important mechanisms of action that are modulated posttranscriptionally. For example, genistein has been reported to reduce cell viability and induce apoptosis, and many signaling events in apoptosis (caspase activation, cytochrome $\mathrm{C}$ release, changes in mitochondrial membrane potential) are not reflected in changes in transcript levels [50]. Adding to the complexity is the importance of the concentration of genistein on transcript profiles. It is likely that genistein metabolism will differ between individuals in a population, and this will directly affect genistein tissue levels and activity. In addition, the optimal dosing schedule and timing of exposure in the lifetime of the individual could influence genistein activity. For instance, it is possible that exposure to during puberty, when the prostate is undergoing androgeninduced growth, might be critical, or that life-long intermittent induction of carcinogen-defense enzymes could be more important in mediating the protective effects of genistein [51]. Future epidemiologic and basic investigations, as well as intervention trials in men at risk for prostate cancer, will be required to address these challenges.

In summary, genistein induces dose-dependent alterations in transcript profiles in human prostate cancer cells in vitro. The altered expression profiles point to growth inhibi- 
tion, activation of carcinogen defenses and steroid signaling pathways as important targets of genistein as a candidate prostate cancer preventive agent. Furthermore, additional pathways, such as PI3K signaling appear to be modulated by physiologically relevant levels of genistein. Investigation of gene expression alterations in prostate tissues after supplementation, such as in men prior to prostate surgery, could help identify the most relevant mechanisms of genistein action in vivo.

\section{ACKNOWLEDGEMENTS}

Supported in part by the United States Army MRMC Prostate Cancer Research Program (DAMD17-98-1-8555), the Doris Duke Foundation (T98064) and NIH CA111782.

\section{CONFLICT OF INTEREST}

The authors have no conflicts of interest to declare.

\section{REFERENCES}

[1] Jemal A, Siegel R, Ward E, Hao Y, Xu J, Thun MJ. Cancer statistics, 2009. CA Cancer J Clin 2009; 59(4): 225-49.

[2] Haenzel W, Kurihara M. Studies of Japanese migrants, I. Mortality from cancer and other diseases among Japanese men in the United States. J Natl Cancer Inst 1968; 40: 43-68.

[3] Brooks JD, Lee W-H, Nelson WG. Epidemiological and molecular features of prostatic carcinogenesis as clues for new prostate cancer prevention strategies. Can J Urol (Suppl) 1996; 3(1): 20-6.

[4] Jacobsen BK, Knutsen SF, Fraser GE. Does high soy milk intake reduce prostate cancer incidence? The Adventist Health Study (United States). Cancer Causes Control 1998; 9(6): 553-7.

[5] Kurahashi N, Iwasaki M, Sasazuki S, Otani T, Inoue M, Tsugane S. Soy product and isoflavone consumption in relation to prostate cancer in Japanese men. Cancer Epidemiol Biomarkers Prev 2007; 16(3): $538-45$

[6] Kurahashi N, Iwasaki M, Inoue M, Sasazuki S, Tsugane S. Plasma isoflavones and subsequent risk of prostate cancer in a nested casecontrol study: the Japan Public Health Center. J Clin Oncol 2008; 26(36): 5923-9.

[7] Taylor CK, Levy RM, Elliott JC, Burnett BP. The effect of genistein aglycone on cancer and cancer risk: a review of in vitro, preclinical, and clinical studies. Nutr Rev 2009; 67(7): 398-415.

[8] Fotsis T, Pepper M, Adlercreutz H, et al. Genistein, a dietaryderived inhibitor of in vitro angiogenesis. Proc Natl Acad Sci U S A 1993; 90(7): 2690-4.

[9] Swami S, Krishnan AV, Moreno J, et al. Inhibition of prostaglandin synthesis and actions by genistein in human prostate cancer cells and by soy isoflavones in prostate cancer patients. Int J Cancer 2009; 124(9): 2050-9.

[10] Raschke M, Rowland IR, Magee PJ, Pool-Zobel BL. Genistein protects prostate cells against hydrogen peroxide-induced DNA damage and induces expression of genes involved in the defence against oxidative stress. Carcinogenesis 2006; 27(11): 2322-30.

[11] Chau MN, El Touny LH, Jagadeesh S, Banerjee PP. Physiologically achievable concentrations of genistein enhance telomerase activity in prostate cancer cells via the activation of STAT3. Carcinogenesis 2007; 28(11): 2282-90.

[12] Rice L, Handayani R, Cui Y, et al. Soy isoflavones exert differential effects on androgen responsive genes in $\mathrm{LNCaP}$ human prostate cancer cells. J Nutr 2007; 137(4): 964-72.

[13] Lazarevic B, Karlsen SJ, Saatcioglu F. Genistein differentially modulates androgen-responsive gene expression and activates JNK in LNCaP cells. Oncol Rep 2008; 19(5): 1231-5.

[14] Harper CE, Cook LM, Patel BB, et al. Genistein and resveratrol, alone and in combination, suppress prostate cancer in SV-40 tag rats. Prostate 2009; 69(15): 1668-82.

[15] Xu L, Ding Y, Catalona WJ, et al. MEK4 function, genistein treatment, and invasion of human prostate cancer cells. J Natl Cancer Inst 2009; 101(16): 1141-55.

[16] Schleicher RL, Lamartiniere CA, Zheng M, Zhang M. The inhibitory effect of genistein on the growth and metastasis of a transplantable rat accessory sex gland carcinoma. Cancer Lett 1999; 136(2): 195-201.

[17] El Touny LH, Banerjee PP. Akt GSK-3 pathway as a target in genistein-induced inhibition of TRAMP prostate cancer progression toward a poorly differentiated phenotype. Carcinogenesis 2007; 28(8): 1710-7.

[18] Jones SB, DePrimo SE, Whitfield ML, Brooks JD. Resveratrolinduced gene expression profiles in human prostate cancer cells. Cancer Epidemiol Biomarkers Prev 2005; 14(3): 596-604.

[19] Zhao H, Brooks JD. Selenomethionine induced transcriptional programs in human prostate cancer cells. J Urol 2007; 177(2): 743-50.

[20] Zhao H, Whitfield ML, Xu T, Botstein D, Brooks JD. Diverse effects of methylseleninic acid on the transcriptional program of human prostate cancer cells. Mol Biol Cell 2004; 15(2): 506-19.

[21] Bhamre S, Sahoo D, Tibshirani R, Dill DL, Brooks JD. Temporal changes in gene expression induced by sulforaphane in human prostate cancer cells. Prostate 2009; 69(2): 181-90.

[22] Peehl DM, Shinghal R, Nonn L, et al. Molecular activity of 1,25dihydroxyvitamin D3 in primary cultures of human prostatic epithelial cells revealed by cDNA microarray analysis. J Steroid Biochem Mol Biol 2004; 92(3): 131-41.

[23] Krishnan AV, Shinghal R, Raghavachari N, Brooks JD, Peehl DM, Feldman D. Analysis of vitamin D-regulated gene expression in LNCaP human prostate cancer cells using cDNA microarrays. Prostate 2004; 59(3): 243-51.

[24] Lapointe J, Li C, Higgins JP, et al. Gene expression profiling identifies clinically relevant subtypes of prostate cancer. Proc Natl Acad Sci USA 2004; 101(3): 811-6.

[25] Sherlock G, Hernandez-Boussard T, Kasarskis A, et al. The Stanford Microarray Database. Nucleic Acids Res 2001; 29(1): $152-5$.

[26] Sahoo D, Dill DL, Tibshirani R, Plevritis SK. Extracting binary signals from microarray time-course data. Nucleic Acids Res 2007; 35(11): 3705-12.

[27] Calvano SE, Xiao W, Richards DR, et al. A network-based analysis of systemic inflammation in humans. Nature 2005; 437(7061): $1032-7$.

[28] Whitfield ML, Sherlock G, Saldanha AJ, et al. Identification of genes periodically expressed in the human cell cycle and their expression in tumors. Mol Biol Cell 2002; 13(6): 1977-2000.

[29] Brooks JD, Goldberg MF, Nelson LA, Wu D, Nelson WG. Identification of potential prostate cancer preventive agents through induction of quinone reductase in vitro. Cancer Epidemiol Biomarkers Prev 2002; 11(9): 868-75.

[30] Brooks JD, Paton VG, Vidanes G. Potent induction of phase 2 enzymes in human prostate cells by sulforaphane. Cancer Epidemiol Biomarkers Prev 2001; 10(9): 949-54.

[31] Prestera T, Zhang Y, Spencer SR, Wilczak CA, Talalay P. The electrophile counterattack response: protection against neoplasia and toxicity. Adv Enzyme Regul 1993; 33: 281-96.

[32] Talalay P, Fahey JW, Holtzclaw WD, Prestera T, Zhang Y. Chemoprotection against cancer by phase 2 enzyme induction. Toxicol Lett 1995; 82-83: 173-9.

[33] Kwak MK, Itoh K, Yamamoto M, Kensler TW. Enhanced expression of the transcription factor Nrf2 by cancer chemopreventive agents: role of antioxidant response element-like sequences in the nrf2 promoter. Mol Cell Biol 2002; 22(9): 2883-92.

[34] Prochaska H, Santamaria A, Talalay P. Rapid detection of inducers of enzymes that protect against carcinogens. Proc Natl Acad Sci USA 1992; 89(6): 2394-8.

[35] DePrimo SE, Diehn M, Nelson JB, et al. Transcriptional programs activated by exposure of human prostate cancer cells to androgen. Genome Biol 2002; 3(7): RESEARCH0032.

[36] Gardner CD, Oelrich B, Liu JP, Feldman D, Franke AA, Brooks JD. Prostatic soy isoflavone concentrations exceed serum levels after dietary supplementation. Prostate 2009; 69(7): 719-26.

[37] Rannikko A, Petas A, Rannikko S, Adlercreutz H. Plasma and prostate phytoestrogen concentrations in prostate cancer patients after oral phytoestogen supplementation. Prostate 2006; 66(1): 82-7.

[38] Gao S, Liu GZ, Wang Z. Modulation of androgen receptordependent transcription by resveratrol and genistein in prostate cancer cells. Prostate 2004; 59(2): 214-25.

[39] Li Y, Sarkar FH. Gene expression profiles of genistein-treated PC3 prostate cancer cells. J Nutr 2002; 132(12): 3623-31. 
[40] Takahashi Y, Lavigne JA, Hursting SD, et al. Using DNA microarray analyses to elucidate the effects of genistein in androgen-responsive prostate cancer cells: identification of novel targets. Mol Carcinog 2004; 41(2): 108-19.

[41] Takahashi Y, Lavigne JA, Hursting SD, et al. Molecular signatures of soy-derived phytochemicals in androgen-responsive prostate cancer cells: a comparison study using DNA microarray. Mol Carcinog 2006; 45(12): 943-56.

[42] Liss MA, Schlicht M, Degueme A, Hessner M, Datta MW. Use of cross species genomic profiling identifies pathways and genes differentially regulated in prostate cancer cells treated with soy protein isolates or purified genistein. Cancer Genomics Proteomics 2010; 7(3): 111-28.

[43] Mori R, Xiong S, Wang Q, et al. Gene profiling and pathway analysis of neuroendocrine transdifferentiated prostate cancer cells. Prostate 2009; 69(1): 12-23.

[44] Brooks JD, Weinstein M, Lin X, et al. CG island methylation changes near the GSTP1 gene in prostatic intraepithelial neoplasia. Cancer Epidemiol Biomarkers Prev 1998; 7(6): 531-6.

[45] Lee WH, Morton RA, Epstein JI, et al. Cytidine methylation of regulatory sequences near the pi-class glutathione S-transferase gene accompanies human prostatic carcinogenesis. Proc Natl Acad Sci USA 1994; 91(24): 11733-7.
[46] Lin X, Tascilar M, Lee WH, et al. GSTP1 CpG island hypermethylation is responsible for the absence of GSTP1 expression in human prostate cancer cells. Am J Pathol 2001; 159(5): 1815-26.

[47] Li TH, Zhao H, Peng Y, Beliakoff J, Brooks JD, Sun Z. A promoting role of androgen receptor in androgen-sensitive and insensitive prostate cancer cells. Nucleic Acids Res 2007; 35(8): 2767-76.

[48] Sarker D, Reid AH, Yap TA, de Bono JS. Targeting the PI3K/AKT pathway for the treatment of prostate cancer. Clin Cancer Res 2009; 15(15): 4799-805.

[49] Tepper CG, Vinall RL, Wee CB, et al. GCP-mediated growth inhibition and apoptosis of prostate cancer cells via androgen receptor-dependent and -independent mechanisms. Prostate 2007; 67(5): 521-35.

[50] Davis JN, Singh B, Bhuiyan M, Sarkar FH. Genistein-induced upregulation of p21WAF1, downregulation of cyclin B, and induction of apoptosis in prostate cancer cells. Nutr Cancer 1998; 32(3): 123-31

[51] Primiano T, Egner PA, Sutter TR, Kelloff GJ, Roebuck BD, Kensler TW. Intermittent dosing with oltipraz: relationship between chemoprevention of aflatoxin-induced tumorigenesis and induction of glutathione S-transferases. Cancer Res 1995; 55(19): 4319-24.

This is an open access article licensed under the terms of the Creative Commons Attribution Non-Commercial License (http://creativecommons.org/licenses/ by-nc/3.0/) which permits unrestricted, non-commercial use, distribution and reproduction in any medium, provided the work is properly cited. 